\title{
NDIS: In context
}

\author{
Marlene Butteriss \\ Griffith University
}

\section{A national disability insurance scheme}

Australia's move toward the development of an insurance scheme that provides the opportunity for Australians with a disability to receive adequate support was initiated at the 2020 summit in 2008. Since that time, a range of actions have been undertaken to bring Australia to the point at which it now stands, on the brink of decision making about the implementation of an National Disability Insurance Scheme (NDIS). The Australian Government has stated its commitment to developing a national disability strategy (Productivity Commission, 2011, p. iv) and it was in this context that the possibility of an NDIS was developed. An NDIS would see the development of an entitlement based scheme that is needs driven and which, quite importantly, sees the person with a disability as the customer, as opposed to the current system which arguably sees the person with a disability as the passive recipient of services.

\section{Why is the NDIS the next logical step for Australia?}

It was not that long ago that people in Australia who had a disability were completely separated from the community. People with disabilities were seen as not being normal. However it can be argued that the idea of normal is not part of human nature and that it is instead a construction of our society (Davis, 2010, p. 3). Attitudes to people with a disability did not begin to change until after the two world wars in the first half of the twentieth century when servicemen who had experienced disablement as a result of war, began to return home (Barnes, 2010, p. 27). But it was not until the 1950's that we began to see a move to reduce segregation, and not until the 1960's in America was there any plan to move people from institutional

How we view impairment and disability has changed dramatically over recent years ... although the impairment a person has is a reality, the disablement is caused by environmental and social barriers.

Figure 1. Excerpt from "Shut Out; The experience of People with disabilities and their families in Australia (NPDCC, 2009, p. 14). settings (Barnes, 2010, p. 29). In 
Australia it was as late as the 1980's before we started to see a move toward deinstitutionalisation. The 1989 report A Place for Everyone (Report of the Ministerial Task Force on Services for People with an Intellectual Handicap in Queensland) set the pathway towards deinstitutionalisation in Queensland with the closure of Challinor Centre at Ipswich (McRobert, 1997, p. 156).

"The closure of institutions and the promise of community inclusion was one of the great policy changes of the 20th century. But the social and economic segregation that has followed is harder to dismantle" (National People with Disabilities and Carer Council [NPDCC], 2009, p. 9), and the majority of people still lead lives isolated from their community and dependent on a broken service system. In 2009, just fewer than one in five people in Australia reported a disability, and of those people approximately 1.3 million (see Figure 2) reported severe or profound core activity limitations (Australian Bureau of Statistics [ABS], 2009).

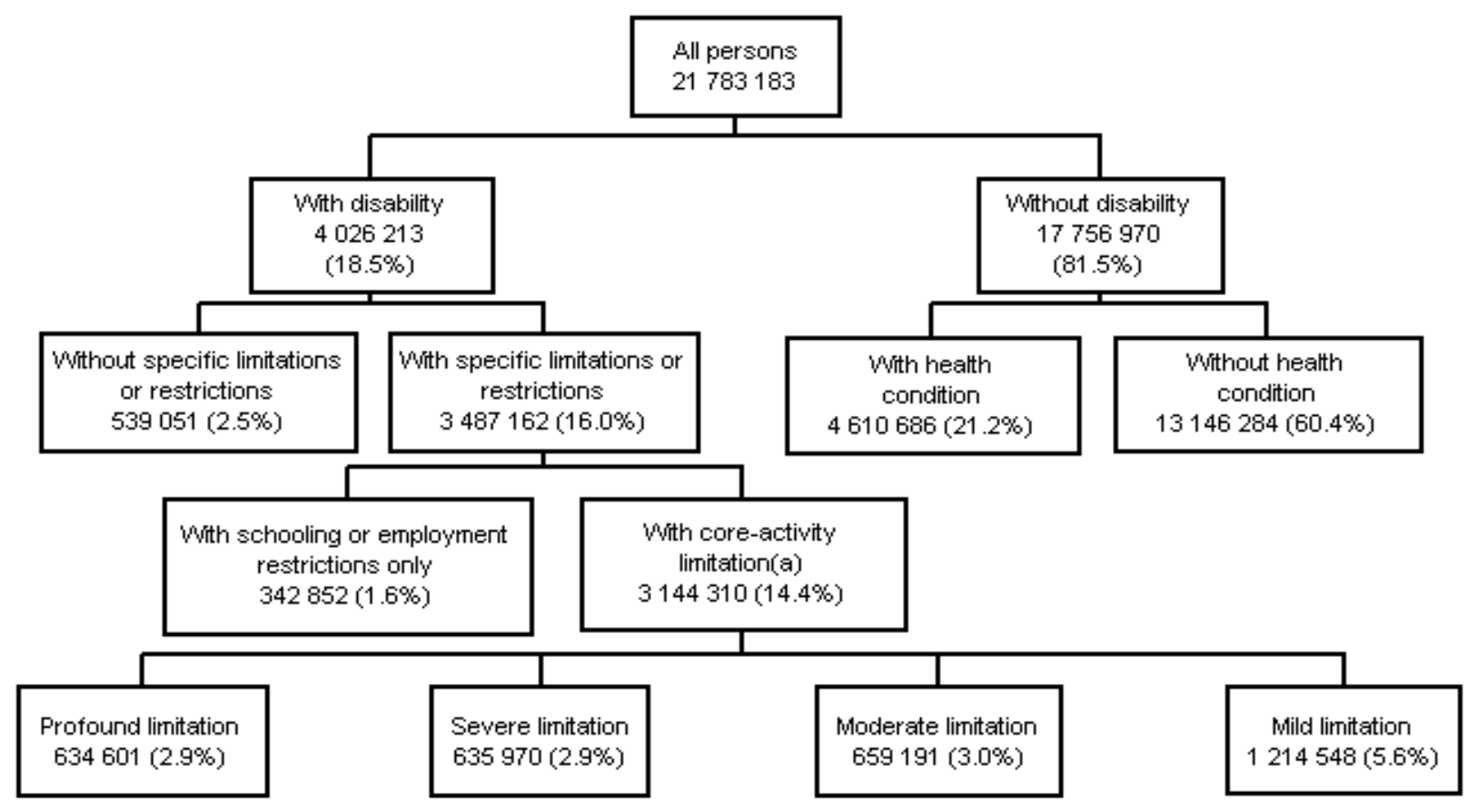

(a) Includes 1345542 persons with core-activity lirnitations and schooling or employment restrictions.

Figure 2. Number of people reported to be effected by disability in Australia 2009.

In Australia, disability support is an area of uncertainty and inconsistency across the states and territories. When a child is born, it is understood that the age of five it will be entitled to education, or if we are sick we are entitled to health care. However there is "no equivalent entitlement to disability care and support services" 
(Productivity Commission, 2011, p. iv). However, there have been some major developments.

One of the most important developments for Australian disability history and policy has been the Commonwealth State and Territory Agreement (CSTDA), now known as the National Disability Agreement (NDA). The first CSTDA was negotiated in 1992; since that time we have seen more acceptance of the fact that States and Territories simply cannot meet the unmet need for disability. The result of this has been a deepening involvement by the Commonwealth in all areas of disability policy (PricewaterhouseCoopers [PWC], 2011, p. 15). This in itself has provided a clear and obvious argument for a National Disability Strategy.

\section{Where does the NDIS fit within the context of current theoretical models?}

In 2008, Australia was "one of the first countries to ratify the United Nations Convention on the Rights of Persons with Disabilities as part of the Australian Government's broader long-term commitment to improving the lives of people with disabilities, their friends and carers" (NPDCC, 2009, p. iv). This was a clear demonstration of Australia's commitment to move toward more of a social model of disability in contrast to the medical model of disability. In such a shift, there is consideration given to the interaction between the person with a disability and the societal barriers which prevent them from full participation, e.g. restrictions placed on a person as a result of paternalistic social welfare systems (McDonald, 2012, p. 2). The NDIS professes to be in line with the social model and is stated as being the "opposite of a welfare model and will make a positive contribution to Australia's productivity" (PWC, 2011, p. 10). In particular, an NDIS states that one of its key components is that of a person with a disability as a customer, which is a long way from the current state of service delivery in Australia. Currently a person with a disability has become the 'passive recipient' of care in Australia and as such has increased vulnerabilities within the

Persons with disability are subject to multiple and aggravated forms of human rights violations, including the neglect of their most basic survival related needs. These human rights violations do not only occur in far off places that lack enlightened legislation and policies, or the resources needed to meet basic needs. They occur every day, in every region, of every state and territory in Australia. Virtually every Australian with disability encounters human rights violations at some points in their lives, and very many experience it every day of their lives.

In 2009, in one of the most enlightened and wealthiest nations in the world, it is possible for persons with disability to die of starvation in specialist disability services, to have life-sustaining medical treatments denied or withdrawn in health services, to be raped or assaulted without any reasonable prospect of these crimes being detected, investigated or prosecuted by the legal system, and to have their children removed by child protection authorities on the prejudiced assumption that disability simply equates with incompetent parenting.

Figure 3. Excerpt from "Shut Out; The experience of People with disabilities and their families in Australia (NPDCC, 2009, p. 15). 
current service system (F. Vickary, personal communication, NDIS Advisory Council Member).

The current system, one in which recipients face a lottery style level of uncertainty about the provision of service, is inherently flawed and places people with a disability in a position in which they can not see themselves as entitled to support and must be grateful for anything they receive. Many people report "significant resentment at constantly being regarded as recipients of charity who should demonstrate considerable gratitude for whatever meagre offerings they receive" (NPDCC, 2009, p. 13). It is these "flaws in the current system that have driven a strong demand for an entirely new system" (Productivity Commission, 2011, p. 7). Alternatively, the Productivity Commission (2011) states that the NDIS would utilise an 'individual choice' model whereby people "could choose how much control the wanted to exercise" and stresses that such a model would not be one which forces people to take full control or none" (p. 30).

\section{Where does Australia fit in relation to disability support compared with the rest of the world?}

Australians with a disability face a lifetime of uncertainty, "in other nations around the world there is a legislated entitlement to support" (NDCA, 2010, p. 2). No such right exists in Australia. Instead "virtually every Australian with a disability encounters human rights violations at some point in their lives and very many experience it every day of their lives" (NPDCC, 2009, p. 4). The state of disability services in Australia (see Figure 4) is particularly underwhelming when compared with other countries. In fact, "forty-five per cent of people with a disability in Australia live in or near poverty, more than double the OECD average of $22 \%$.

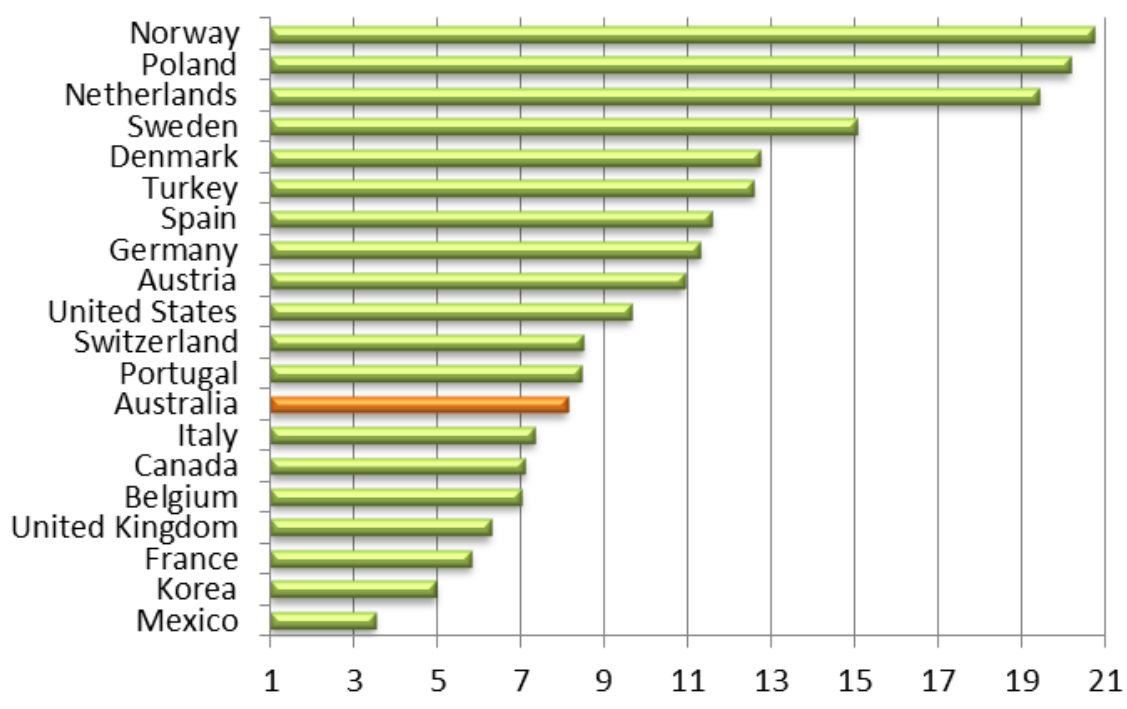

Figure 4. Percentage of total public social expenditure spent on disability. Source OECD, 2003. 
Furthermore, Australia has a relative poverty risk (i.e. people with a disability compared to people without a disability) of 2.7, against the OECD average of 1.6 " (PWC, 2011, p. 9). "In an international comparison of disability related expenditure (to the extent that this is possible) indicates that, compared with other countries, Australia has a lower level of spending as a share of GDP on long term care for people under the age of 65" (PWC, 2011, p. 9). Service delivery in a cultural context within Australia is inadequate and "can hit certain communities particularly hard, such as people in regional and remote areas, people from non-English speaking backgrounds and Indigenous people" (Productivity Commission, 2011, p. 6).

\section{Conclusion}

In terms of a context for an NDIS in Australia, such a scheme is aimed at maximising social and economic participation of people with a disability, and provides a policy context for disability reform. Inside of that, Queensland (QLD) has indicated its commitment to greater choice and control for people with a disability and has voiced a commitment to individual funding $(\mathrm{H}$. Ferguson, ED, Policy and Performance, Disability and Community Care Services, personal communication, January 23, 2012). The introduction of an NDIS will be the catalyst for disability reform in Australia.

\section{References}

Australian Bureau of Statistics [ABS] (2009). Survey of disability, ageing and carers, summary of findings (cat. no. 4430.00). Canberra: ABS. Retrieved from http://www.abs.gov.au/ausstats/abs@.nsf/Latestproducts/4430.0Main\%20Fea tures 12009? opendocument\&tabname $=$ Summary\&prodno $=4430.0$ \&issue $=200$ 9\&num $=\&$ view $=$

Barnes, C. (2010). A brief history of discrimination and disabled people. In L. J. Davis (Ed.), The disability studies reader ( $3^{\text {rd }}$ ed., pp. 20-32). London: Routledge.

Davis, L. (2010). Constructing normalcy. In L. J. Davis (Ed.), The disability studies reader ( $3^{\text {rd }}$ ed., pp.3-16). London: Routledge.

McDonald, D. (2012). HSV7015 conversations about disability week 2: Theoretical models for understanding disability. Retrieved from Griffith University, Learning@Griffith web site:

https://learning.secure.griffith.edu.au/webapps/portal/frameset.jsp?tab=course s\&url=/bin/common/course.pl?course_id=_105819_1\&frame=top

McRobert, E. (1997). Challinor centre: The end of the line: A history of the institution also known as Sandy Gallop. Brisbane, Queensland: Department of Families, Youth \& Community Care. 
National People with Disabilities and Carer Council [NPDCC]. (2009). Shut out: The experience of people with disabilities and their families in Australia. Canberra: Commonwealth of Australia.

Organisation for Economic Co-operation and Development [OECD]. (2003). Transforming disability into ability; policies to promote work and income security for disabled people (OECD publications, Paris, France). Retrieved from http://www.oecd.org/document/14/0,3746,en $26493392735290126 \quad 1 \quad 11$ 1,00.html

PricewaterhouseCoopers [PWC]. (2011). Disability expectations: Investing in a better life, a stronger Australia. Retrieved from

http://www.pwc.com.au/industry/government/publications/disability-inaustralia.htm

Productivity Commission. (2011). Disability care and support (Report No. 54). Canberra.

National Disability and Carer Alliance [NDCA]. (2010, August). The importance of a social insurance approach to disability funding. Submission to the Productivity Commission Disability Care and Support Inquiry.

\section{Biographical Notes}

Marlene Butteriss has significant lived and professional experience in the disability sector in Australia. Ms Butteriss has over 22 year's professional background in both government and non government organisation. Predominantly working and living in south east Queensland, Ms Butteriss has also worked in the disability sector in North Queensland, Northern territory and Western Australia. Ms Butteriss holds a BA with majors in Anthropology and in Archaeology and Paleoanthropology, and is currently working on her masters in Human Services with a specialty in Disability Studies. 